\title{
Brief Problem-solving Treatment in Primary Care (PST-PC) Was Not More Effective than Placebo for Elderly Patients Screened - Positive of Psychological Problems
}

Running Title: PST-PC for psychological problems in the elderly

Cindy L.K. Lam*, MBBS, MD (HK), FRCGP, FHKAM (Family Medicine)

Clinical Professor, Family Medicine Unit, The University of Hong Kong Daniel Y.T. Fong, PhD

Assistant Professor, Department of Nursing Studies, The University of Hong Kong Weng-Yee Chin, MBBS, FRACGP,

Assistant Professor, Family Medicine Unit, the University of Hong Kong Peter W.H. Lee, PhD

Hon. Professor, Department of Psychiatry, The University of Hong Kong Elegance TP Lam, BSc, MMSc.

Ph D Candidate, Family Medicine Unit, The University of Hong Kong Yvonne YC Lo, MBchB, FRACGP, FHKCFP, FHKAM (Family Medicine) Clinical Assistant Professor, Family Medicine Unit, The University of Hong Kong

* Correspondence: Cindy L.K. Lam, Family Medicine Unit, HKU, 3/F., Ap Lei Chau Clinic, 161 Main Street, Ap Lei Chau, Hong Kong SAR. Tel: 852-25185653; Fax: 852-28147475.

E mail: clklam@hku.hk 


\section{Ethics Approval}

This research project was approved by the Ethics Committee of the Faculty of Medicine, the University of Hong Kong (EC 1293-99).

\section{Clinical Trial Registration}

ClinicalTrials.gov HKCTR-497.

\section{Funding}

This project was supported by the Health Care and Promotion Fund (project ref no \# 218016) of the Food and Health Bureau, the Government of the Hong Kong SAR

\section{Acknowledgements}

We would like to thank Dr. Stephen W.K. Chow, Dr. Kevin K.L. Pang, Dr. Johnny C.Y. Lam, Dr. Sam C.S. Au, Dr. Jacky H.H. Sze and Dr. Brigitte E. Schlaikier for providing the PST-PC. Thanks to On-On Cheng and Alice O.L. Cheung for their assistance in data collection and analysis.

\section{Conflict of Interest}

None 


\section{Abstract}

Objectives: To evaluate whether screening followed by brief problem-solving treatment by primary care doctors (PST-PC) could improve health-related quality of life (HRQOL) and reduce consultation rates in the elderly.

Design: A single-blind randomised placebo controlled trial (RCT)

Setting: Two Government funded primary care clinics in Hong Kong.

Participants: 299 Chinese patients aged 60 years or over, with positive screening scores for psychological problems by the Hospital Anxiety and Depression Scale (HADS).

Interventions: 149 subjects were randomised to receive brief problem-solving treatment (PST-PC) from primary care doctors (treatment) and 150 to group video-viewing (placebo). All subjects were followed up by telephone at $6,12,26$ and 52 weeks.

Main Outcome Measures: Changes in SF-36 HRQOL scores, HADS scores and monthly consultation rates were compared within and between groups.

Results: Study completion rates were $69-71 \%$. There was significant improvement in the SF-36 role-emotional (RE) and mental component summary (MCS) scores at week 6 in the PST-PC group but not in the placebo group. Several SF-36 scores improved significantly in the placebo (video) group at weeks 6 to 52. Mixed effects analysis adjusting for baseline values and cofounders did not show any difference in any of the outcomes between the PST$\mathrm{PC}$ and placebo (video) groups

Conclusions: Screening followed by brief PST-PC was associated with a short-term improvement in HRQOL in Chinese elderly patients screened positive of psychological problems, but the HRQOL benefit was not greater than those found in the placebo group who participated in group-viewings of health education videos.

Word Count: 3499

Keywords: mental illness, problem solving treatment, primary care, screening, elderly, Chinese 


\section{Brief Problem-solving Treatment in Primary Care (PST-PC) Was Not More Effective than Placebo for Elderly Patients Screened Positive of Psychological Problems}

\section{Introduction}

Psychological problems are often unrecognized and inadequately managed in the elderly (Hirschfeld, 2001, Lam, 1995, Liu et al., 2004, Streiner et al., 2006, Harman et al., 2005). Screening for depression in high risk groups is recommended for earlier detection and better mental health outcomes (U.S. Preventive Services Task Force, 2002, Farsides and Dunlop, 2001, National Institute for Clinical Excellence (NICE), 2004). To date, studies have shown that screening enhances detection but without significant improvements to health (Callahan, 2001, Gilbody et al., 2001) due in part to the uncertainty of how best to manage these patients. Drugs are commonly used, but are of doubtful benefit for the mild psychological problems typical of screened-positive cases and can have adverse effects especially in the elderly (Hirschfeld, 2001, Hunkeler et al., 2006, National Institute for Clinical Excellence (NICE), 2004, Kennedy et al., 2003, Spigset, 1999, Callahan, 2001). Although many elderly patients prefer psychological treatments (Gum et al., 2006), non-drug interventions are probably underused (National Institute for Clinical Excellence (NICE), 2004) and provision of psychological treatments in primary care can be difficult due to lack of time and expertise. NICE recommends that a stepped-care approach with a trial of psychological treatment before drugs (??) to match the needs of the patients

Problem-solving treatment in primary care (PST-PC) is a psychological therapy designed to be provided by primary care workers after a short training course (Hegel et al., 2004, Cape et al., 2000b, Kennedy et al., 2003, Arean et al., 2008). It is a generic treatment which can be used in various psychological problems including depression, anxiety, and sleep disturbance (Malouff et al., 2007, Mynors-Wallis, 2001, Dowrick et al., 2000a) and can be 
used at the step 2 stage of the NICE recommended stepped care. Mynors-Wallis et al showed that PST-PC was as effective as antidepressants in improving symptoms and social functioning of patients with depression (Mynors-Wallis et al., 2000). Although four to six sessions of PST-PC are usually recommended, benefit has been found with as few as three (Arean et al., 2008, Hegel et al., 2004, Mynors-Wallis et al., 2000).

The aim of our study was to determine whether screening followed by brief (three sessions) PST-PC provided by primary care doctors could improve quality of life and reduce consultation rates in elderly patients with unrecognized psychological problems.

\section{Methods and subjects}

This was a single-blind randomised placebo controlled trial (RCT) in patients from two Government-funded general outpatient clinics (GOPC) in Hong Kong. Over 70\% of the elderly in Hong Kong use GOPCs for their usual primary care, (Census \& Statistics Department, 2001) 99\% being Chinese and more than 50\% being elderly with chronic diseases.

\section{Subjects}

All Chinese patients aged 60 or above consulting the two GOPCs of one district in Hong Kong were invited to an initial screening study. Patients were excluded if they had a known doctor-diagnosed psychological disease, history of taking psychotropic medications within the last year, suicidal plans or strong suicidal thoughts, psychotic symptoms, cognitive impairment or communication problem, or had already been recruited to the study on a previous clinic visit. Details of the sampling population and method are described in an earlier paper (Lam et al., 2009). All eligible patients were screened with the Hospital Anxiety and Depression Scale (HADS) and those with 
positive HADS scores were invited to participate in the RCT. The estimated sample size was 300 subjects (150 each for the PST-PC and placebo groups) to detect a moderate effect size $(0.5 \mathrm{SD})$ difference in HRQOL scores between groups by independent t test with a power of $80 \%$ and $95 \%$ confidence interval, allowing for a dropout rate of $40 \%$.

The numbers of patients initially screened, recruited and followed up are shown in Figure 1. The response rate to the initial screening was $71.9 \%$. Of the 2020 patients who completed the initial interview, 482 screened positive with the HADS. These patients were found to have poorer (lower) SF-36 scores and higher consultation rates than screened-negative subjects and the general elderly population (Lam et al., 2009). $299(62.0 \%)$ screened-positive patients agreed to join the RCT. $132(88.6 \%)$ subjects in the PST-PC group attended at least one session with 109 (73.2\%) completing all three sessions. $132(88.0 \%)$ of the placebo (video) group attended at least one session with 113 (75.3\%) completing all three sessions. The follow-up rates at 52 weeks were in the PSTPC group $69 \%$ and $71 \%$ in the placebo (video) group.

\section{Study Instruments}

The Cantonese version of the Hospital Anxiety and Depression Scale (HADS) (Zigmond and Snaith, 1983, Lam et al., 1995), the Chinese (HK) SF-36 Health Survey (Lam et al., 1998, Lam et al., 1999) and a questionnaire on service utilization, chronic morbidity and socio-demography were administered to each subject. HADS cutoff scores of Anxiety Score (AS) $\geq 3$ or Depression Score (DS) $\geq 6$ were used to identify screened-positive cases of psychological problems. Using these cut-offs, the HADS has a sensitivity of $80 \%$ and a specificity of $90 \%$ in Chinese elderly primary care patients (Lam et al., 1995). The Chinese (HK) SF-36 Health Survey is a generic measure of HRQOL that gives eight scale and two (physical and mental) component summary scores (PCS and MCS), with higher scores indicating better quality of life (Ware et al., 1993). 


\section{Randomization and Interventions after Screening}

Subjects with positive HADS scores (AS $\geq 3$ or DS $\geq 6$ ) were invited by telephone to particpate in the randomised control trial (RCT). Those who agreed were randomised into either the intervention (PST-PC) group or the placebo (video) group. The randomisation schedule was computer-generated by permuted block randomization, with block size randomised between 4 and 8 , by a statistician who did not take part in the recruitment, treatment or assessment of the subjects.

Each subject in the PST-PC group returned to the clinic to see a Family Medicine trainee who was not involved in the usual care of the patient for three PST-PC sessions at week 1, 3 and 5 from time of screening. The PST-PC was modified from that used by Mynors-Wallis et al (Mynors-Wallis et al., 2000). Session one lasted 30 to 45 minutes during which the doctor completed the three core tasks of PST-PC: 1. establishment of a positive therapeutic relationship, 2. developing a shared understanding of the problem, and 3. promoting change in behaviour, thoughts and emotions (Cape et al., 2000b, Cape et al., 2000a). Sessions two and three each lasted for 20 to 30 minutes during which the doctor assessed the patient's progress, answered questions and reinforced the patient's coping behaviours and positive thinking. A semi-structured record form incorporating the seven steps of PST-PC was used to monitor treatment process during each session (Appendix A).

A total of six trainees underwent the training program consisting of three 3-hour workshops conducted by a clinical psychologist and a package of reading materials on the diagnosis of mental illnesses and principles of psychological treatments. All sessions were video-taped and a random sample of the first sessions of three different patients per doctor was assessed by the psychologist with a structured rating form on the quality of the PST-PC. 
The assessment sessions showed that the doctors were able to establish a positive therapeutic relationship in $94.5 \%$, developed a shared understanding of the problem in $88.9 \%$, and promoted changes in thinking or behaviour in $83.3 \%$ of the sessions.

Subjects randomised to the placebo (video) group were invited to attend the clinic in groups of three to six at weeks 1,3 and 5 to watch health education videos for 30 minutes in the first session (healthy diet) and 20 minutes in each of the last two sessions (exercise, and physical \& psychological health).

All subjects continued to receive their usual medical care.

\section{Follow-up Assessments and Blinding}

Each subject was followed up by telephone 6, 12, 26 and 52 weeks after initial screening. The same survey instruments (excluding socio-demography) were administered at each follow up by a trained interviewer who was blinded to the screening result, group allocation or treatment of the subject.

\section{Outcome Measures and Data Analysis}

The primary outcomes were the Chinese (HK) SF-36 scale and summary scores. Secondary outcomes included the HADS scores and number of consultations in the past one month (consultation rate). The subjects' global perception of benefit to their general and psychological health was also evaluated.

For each outcome, the change from baseline was estimated by a linear mixed effects model that takes account of the repeated measurements per patient. The Holm's procedure was used to account for multiplicity due to multiple comparisons across different weeks from baseline (Holm, 1979). Adjustment for baseline difference, socio-demographics and comorbidities was also made. 
To assess the difference between PST-PC and placebo groups on each outcome, a linear mixed effects analysis was again used. Both the intercept and week were taken as random effects and their association was left unstructured. The indicator variable for group and the baseline value of the outcome variable were included as fixed effects. The potential difference of the between-group difference across different weeks was examined by an interaction term which was removed if insignificant before the main effects were reported. Normality of residuals and random effects were checked. Adjustment for the effects of baseline imbalance, socio-demographics, and co-morbidities, was also made to remove the effects from potential prognostic factors. Consistent to the intention-to-treat (ITT) principle, missing values were replaced by the last observed value. The analysis was repeated on subjects with missing values ignored. To account for multiplicity due to multiple analyses of the eight scales and two component summary scores of the SF-36, the Holm's procedure was used for considering statistical significance (Holm, 1979).

The statistical analysis was performed by the SAS 9 and the SPSS for Windows 15.0. The level of significance was taken as 0.05 . All estimates were accompanied by a $95 \%$ confidence interval, where appropriate.

\section{Results}

All results based on the ITT principle were similar to those after ignoring the missing values in terms of the effect estimates, and all conclusions remained essentially the same. Therefore, we present only those results based on ITT.

Table 1 shows the baseline characteristics of the study subjects, overall and by groups. There was no difference between the PST-PC and placebo (video) groups except a higher mean HADS depression score (DS) and lower mean SF-36 mental health $(\mathrm{MH})$ in the PST-PC group. Those who refused further intervention (Refused RCT) had 
similar HADS scores but lower SF-36 physical functioning (PF) score and fewer episodic consultations than participants of the RCT.

\section{Change in SF-36 HRQOL Scores, HADS Scores and Monthly Consultation Rates}

The overall changes in SF-36 scores, HADS scores and consultation rates over time are shown in Table 2. The changes after adjustment for DS and $\mathrm{MH}$ at baseline as well as socio-demographics and co-morbidities (not shown) were very similar and their significance levels were essentially the same except for those indicated in the table. There were significant improvements in the SF-36 mental component summary (MCS) score and the role-emotional (RE) score from baseline to week 6 in the PST-PC group, which were not found in the placebo (video) group. There was no significant change in any SF-36 scores at $26^{\text {th }}$ and $52^{\text {nd }}$ weeks in the PST-PC group. Several SF-36 scores increased significantly at the 6 th, $12^{\text {th }}$ and 26th weeks and the improvement in bodily pain (BP) and RE scores persisted until the $52^{\text {nd }}$ week in the placebo (video) group.

The anxiety scores (AS) at all follow-up assessments were significantly lower (improved) than baseline for both the PST-PC and placebo (video) groups. On the other hand, the depression score (DS) increased with time, which was statistically significant in the placebo (video) at all times but not significant in the PST-PC group until the $52^{\text {nd }}$ week.

The proportion of HADS positive cases in the PST-PC and video groups dropped at 6 weeks to $71 \%$ and $63 \%$, respectively, and remained at similar prevalence $(71 \%$ and $65 \%$, respectively) until $52^{\text {nd }}$ week. There was no significant change to any of the consultation rates in both groups.

Table 3 summarizes the effects of PST-PC over placebo (video) on the changes in the outcomes measured after baseline. Among all the outcome variables, the SF-36 RE score was the only outcome in which the difference between PST-PC and placebo (video) groups 
differed across weeks ( $p=0.002$ for the group by time interaction). After accounting for multiplicity, PST-PC was less effective than placebo (video) in improving the SF-36 BP in all follow-up visits and the RE score at week 52. However, the effects became insignificant after the adjustment of HADS DS and SF-36 MH score at baseline as well as the sociodemographics and co-morbidities.

\section{Evaluation of the Interventions}

A global evaluation on the interventions was performed at week 6 . The results are shown in table 4. Only a minority of subjects thought the PST-PC improved their general health $(33 \%)$ or psychological health (39\%) although $73 \%$ wished their family doctors could provide a similar service. A significantly higher proportion of subjects in the placebo (video) group perceived the intervention to be beneficial to their general health ( $51 \%$ vs. $33 \%)$ and were willing to take part again (65\% Vs. $51.8 \%)$.

\section{Discussion}

This study evaluated PST-PC as a treatment for psychological problems detected by screening without differentiation between different psychiatric diagnoses to simulate primary care where psychological problems often do not conform to specific DSM diagnosis (Hirschfeld, 2001, The MaGPIe Research Group, 2005, Nease et al., 1999). The HADS was chosen as the case finding instrument since it performs better than most other screening instruments and can detect different psychological problems in primary care (Nease and Malouin, 2003, Bjelland et al., 2002, Lam et al., 1995). Dowrick et al found that specific diagnosis does not make any difference to the outcome of PST-PC (Dowrick et al., 2000b). 


\section{Effectiveness of PST-PC}

Most previous studies on the treatment of psychological problems have used symptom scores as the primary outcome measure whose clinical significance may be hard to interpret. We used health-related quality of life and consultation rate as primary outcome measures because they are better indicators of the impact of illness on health and service.

In our study, PST-PC resulted in short-term (6 and 12 weeks) improvements to the SF$36 \mathrm{MCS}$ and RE scores that measure mainly mental health-related quality of life, supporting the validity of the results. RE refers to the limitations of daily role funcitioning as a result of emotional problems (Ware and Sherbourne, 1992). These benefits were not found in the placebo (video) group indicating that a true therapeutic effect was likely. However, the HRQOL benefit became insignificant by week 26 and 52 . In the study by Dowrick et. al, improvements in SF-36 scores were found up to 6 months but not at 12 months (Dowrick et al., 2000a). The IMPACT study found more sustained improvements in depressive symptoms of up to 12 months but benefits disappeared at 24 months (Arean et al., 2008). Of note, IMPACT subjects received additional maintenance group treatments, psycho-education, psychotherapy and care co-ordination, and were probably more motivated since they chose to receive PST-PC over medication or watchful waiting. In general, most studies on PST-PC have reported short term benefits immediately after completion of treatment, but long term outcomes remain unclear (Williams et al., 2000, Mynors-Wallis et al., 2000).

$29 \%$ of the PST-PC group and $37 \%$ of the placebo group changed from a positive to a negative HADS case at week 6 with the resolution persisting until week 52. This may have resulted from the interventions but it could also be a reflection of the natural history of mild psychological problems. Dowrick et al found that up to $41 \%$ of the positive cases of depression became negative even without intervention (Dowrick et al., 2000a). 
The HADS anxiety score decreased significantly in both groups at all times until week 52 but the depression score (DS) increased suggesting the interventions had differential effects. Increases in the DS were significant in the placebo group at all follow-up points, but was not significant in the PST-PC group until week 52. It is possible that PST-PC slowed the deterioration of depressive symptoms.

There are a number of reasons why our study failed to show more significant benefits from PST-PC? Firstly, PST-PC is possibly less useful for screened-positive cases than for clinically diagnosed depression. A recent Dutch RCT on frequent primary care attendees screened positive of mental health problems did not find PST provided by nurses more beneficial than usual care in improving symptoms or reducing consultation rate (Schreuders et al., 2007). Williams et al also found PST-PC had no benefit for elderly with dysthymia or minor depression with little functional impairment (Williams et al., 2000).

Another reason is that our patients were not given an option regarding treatment. Studies have shown that patients who are provided with choices and choose counseling themselves do better than those who have been randomised to it (Chilvers et al., 2001, Mynors-Wallis, 2001). A review into depression delivery models found that incorporation of patient preferences into care was associated with improved outcomes (Griffiths and Christensen, 2009).

Finally there is the influence of culture. PST-PC was originally developed in the UK and has been studied predominantly in Western patients. Chinese patients behave differently from their Western counterparts when dealing with mental problems. Chinese elderly often somatise and attribute symptoms to physical disease. They do not acknowledge psychological distress easily, and prefer to avoid engaging in discussions of their psychological state. These behaviours can impact PST-PC outcome, as early identification for the rationale behind treatment has been found to be a positive predictor to response (Hegel et al., 2002). Chinese 
elderly patients also prefer a passive approach to medical care which also affects PST-PC outcomes as active participation is required.

\section{PST-PC by Primary Care Doctors}

Our study showed that young Family Medicine trainees were able to acquire the skills of PST-PC over a short 9-hour course. Evaluation of the PST-PC sessions showed that our doctors were able to achieve the three core tasks of PST-PC in nearly $90 \%$ sessions. The immediate improvement in patients' SF-36 MCS and RE scores and the more sustained reduction in the HADS AS were evidence in support of their competence. Unfortunately, the patients' health benefits were only modest and transient. One reason for this might be that the 'dose' of three sessions may have been insufficient. In reality however, the feasibility of providing more than three sessions would be low due to the excessive burden on professional manpower as well as reduced likelihood of patient adherence. In the study by Mynors-Wallis et al, most subjects did not complete the intended 6 sessions (mean 4.5) and many attended three or fewer sessions (Mynors-Wallis et al., 2000). A more feasible way of enhancing and sustaining the benefit of PST-PC would be by providing ongoing reinforcement ('booster') sessions incorporated longitudinally with subsequent regular care. The IMPACT study found that patients who were able to receive monthly maintenance group treatments ('booster sessions') following four to six sessions of PST achieved the greatest benefits (Arean et al., 2008).

To avoid contamination, the doctor giving PST-PC was not the one providing the patient's usual care. The therapeutic effect is likely to be greater if PST-PC can be provided by the patient's own family doctor. Family doctors with more life and professional experience may also be more effective than our young trainees. Furthermore, most of our subjects were female but five out of six PST-PC doctors in this study were male. The scope of this study did 
not allow the exploration on the effect of doctor characteristics on the outcome of PST-PC, which deserves more research.

\section{Placebo Intervention of Group Viewing of Health Education Videos}

It was surprising to find that our placebo intervention of video viewing was just as effective as PST-PC. Most studies showing effectiveness of PST-PC have compared it against usual care, watchful waiting or placebo drug (Malouff et al., 2007, Mynors-Wallis et al., 2000, Cape et al., 2000a, Williams et al., 2000). Studies comparing PST-PC against active treatments including antidepressants, psycho-education or other psychological treatments have mostly shown no superior effect (Dowrick et al., 2000a, Malouff et al., 2007, Mynors-Wallis et al., 2000). The placebo and Hawthorn effects from any intervention can be quite significant in patients with psychological problems, and simple interventions with minimal professional input may prove to be as effective as intensive psychological treatments.

It was interesting to find that the placebo (video) group had more cases becoming HADS negative, and more improvements in several SF-36 HRQOL scores than the PST-PC group. It is possible that viewing health education videos in small groups might have more than just a placebo effect through the promotion of healthy life style, social interaction and mutual support. This might explain why the improvements were mainly in the functioning and bodily pain domains instead of the mental health domain. The effect could be similar to interpersonal therapy that has been found to be as effective as PST-PC (Bower, 2002, Alexopoulos et al., 2003). Patient acceptance and rating of video viewing was higher than that of PST-PC with more patients agreeable to attending similar sessions in the future. Further studies assessing the effectiveness of such simple activities are needed and if proven effective could easily be implemented into practice. 


\section{Limitations}

All subjects in our study were Chinese. We believe our results can be generalizable to other Chinese elderly primary care patients with psychological problems detected on screening in Asian settings, but may not be generalizable to other elderly patients internationally.

In this study, PST-PC was delivered by Family Medicine residents who were not involved in the patients' usual care. The therapeutic effect might have been greater if PST-PC was provided by a doctor who had a long term relationship with the patient, or who had more life and professional experience than our young trainees.

Classification by the HADS was not $100 \%$ accurate and no attempt was made to establish specific psychiatric diagnoses, which could have diluted the treatment effects. It is not known whether the treatment could be more effective for specific conditions such as major depression or for patients with more severe illnesses. The limited effectiveness of PSTPC should not be extrapolated to other psychological treatments.

\section{Conclusions}

Our study showed that Family Medicine trainees were able to successfully acquire the skills of PST-PC over a short 9 hour course that should be feasible to be incorporated into Family Medicine residency programs. A qualitative exploration of our doctors' perceptions of their training and provision of PST-PC and its impact on their future practice was not within the scope of this study but will be the subject of a future paper.

Screening followed by three sessions of brief PST-PC by primary care doctors was associated with a short-term improvement in mental health related quality of life (SF-36 MCS and RE scores) in elderly patients with previously unrecognized psychological problems, but benefits were not significantly better than a placebo intervention of group viewing of 
educational videos. Three treatment sessions might not be sufficient for sustained benefit and more sessions or opportunistic 'boosters' of PST-PC during regular consultations should be considered if such a treatment is being used.

In view of the relatively high demand on manpower and modest acceptance by patients, our recommendation is that PST-PC should not be used in the routine treatment for all elderly with screened-positive psychological problems. Instead, we propose that PST-PC should be considered as a treatment option in a stepped care approach for selected patients who have not recovered following usual care.

Viewing of health education videos in small groups was associated with significant improvements in HRQOL and remission of psychological problems in the elderly. These simple strategies, as well as the reasons for the poor acceptability of PST-PC among such patients, are areas which require further evaluation. 


\section{Figure 1. Distribution \& Follow up of Study Subjects}

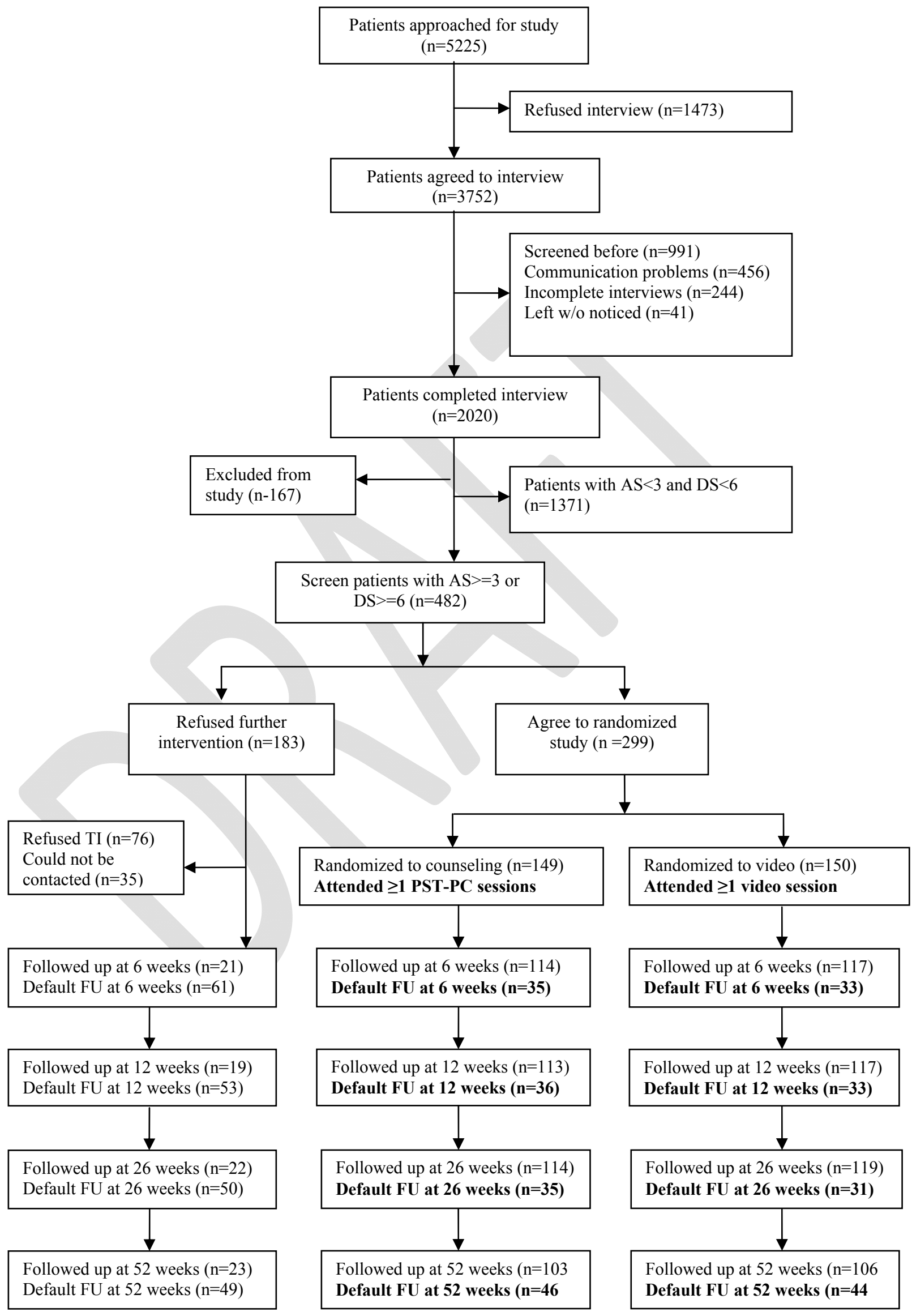


Table 1. Baseline Characteristics of Subjects

\begin{tabular}{|c|c|c|c|c|}
\hline & $\begin{array}{l}\text { PST-PC } \\
(n=149)\end{array}$ & $\begin{array}{l}\text { Placebo } \\
\text { (Video) } \\
(\mathrm{n}=150)\end{array}$ & $\begin{array}{c}\text { Refused } \\
\text { RCT } \\
(\mathrm{n}=72)\end{array}$ & $\begin{array}{c}\text { Total } \\
(n=371)\end{array}$ \\
\hline Age, in years, mean $\pm \mathrm{SD}$ & $71.6 \pm 6.5$ & $72.0 \pm 7.0$ & $71.2 \pm 7.8$ & $71.7 \pm 7.0$ \\
\hline Male/ female, $\%$ & $45.0 / 55.0$ & $41.3 / 58.7$ & $31.9 / 68.1$ & $41.0 / 59.0$ \\
\hline No formal/ any education, $\%$ & $55.7 / 44.3$ & $51.3 / 48.7$ & $65.3 / 34.7$ & $55.8 / 44.2$ \\
\hline \multicolumn{5}{|l|}{ Marital status, \% } \\
\hline Married, living with spouse & 65.8 & 61.3 & 68.1 & 64.4 \\
\hline Other status & 34.2 & 38.7 & 31.9 & 35.6 \\
\hline \multicolumn{5}{|l|}{ Occupation, $\%$} \\
\hline Prof/ Ass. Prof./ Skilled & 6.2 & 8.7 & 1.4 & 6.3 \\
\hline Semi-skilled/ Elementary & 93.8 & 91.3 & 98.6 & 93.7 \\
\hline \multicolumn{5}{|l|}{ Presence of chronic diseases, $\%$} \\
\hline Yes / No & $84.6 / 15.4$ & $84.0 / 16.0$ & $90.3 / 9.7$ & $85.4 / 14.6$ \\
\hline$\leq 2$ diseases & 72.5 & 76.0 & 83.3 & 76.0 \\
\hline$>2$ diseases & 27.5 & 24.0 & 16.7 & 24.0 \\
\hline \multicolumn{5}{|l|}{ HADS Scores, mean \pm SD } \\
\hline AS & $5.0 \pm 3.7$ & $4.7 \pm 2.8$ & $4.5 \pm 3.0$ & $4.8 \pm 3.2$ \\
\hline DS & $4.9 \pm 4.4^{*}$ & $3.9 \pm 3.5^{*}$ & $4.3 \pm 3.5$ & $4.4 \pm 3.9$ \\
\hline \multicolumn{5}{|l|}{$\mathrm{SF}-36$ Scores, mean $\pm \mathrm{SD}$} \\
\hline $\mathrm{PF}$ & $68.2 \pm 22.5$ & $71.86 \pm 21.1$ & $64.2 \pm 21.4 \dagger$ & $68.9 \pm 21.9$ \\
\hline $\mathrm{RP}$ & $58.2 \pm 43.1$ & $55.16 \pm 41.8$ & $52.8 \pm 42.5$ & $55.9 \pm 42.4$ \\
\hline $\mathrm{BP}$ & $63.7 \pm 31.8$ & $63.56 \pm 31.3$ & $59.0 \pm 31.6$ & $62.7 \pm 31.5$ \\
\hline $\mathrm{GH}$ & $45.7 \pm 24.1$ & $48.18 \pm 23.2$ & $47.7 \pm 22.6$ & $47.1 \pm 23.4$ \\
\hline VT & $53.6 \pm 22.4$ & $57.03 \pm 21.5$ & $56.7 \pm 18.3$ & $55.6 \pm 21.3$ \\
\hline SF & $75.5 \pm 29.1$ & $78.83 \pm 29.8$ & $78.1 \pm 27.7$ & $77.4 \pm 29.1$ \\
\hline RE & $60.2 \pm 45.6$ & $65.55 \pm 43.4$ & $68.5 \pm 41.4$ & $64.0 \pm 44.0$ \\
\hline MH & $65.1 \pm 20.6^{*}$ & $69.94 \pm 21.5^{*}$ & $67.3 \pm 19.2$ & $67.5 \pm 20.8$ \\
\hline PCS & $36.8 \pm 13.6$ & $37.10 \pm 13.2$ & $33.8 \pm 12.8$ & $36.4 \pm 13.3$ \\
\hline MCS & $49.2 \pm 12.3$ & $51.66 \pm 12.9$ & $52.7 \pm 10.3$ & $50.9 \pm 12.2$ \\
\hline \multicolumn{5}{|l|}{ Monthly consultations, mean \pm SD } \\
\hline WM episodic consultation & $0.8 \pm 1.1$ & $0.9 \pm 1.2$ & $0.6 \pm 0.9 \dagger$ & $0.8 \pm 1.1$ \\
\hline All WM consultation & $1.4 \pm 1.1$ & $1.452 \pm 1.3$ & $1.2 \pm 1.1$ & $1.4 \pm 1.2$ \\
\hline CM consultation & $0.2 \pm 1.0$ & $0.44 \pm 1.6$ & $0.4 \pm 1.7$ & $0.3 \pm 1.4$ \\
\hline Total consultation & $1.6 \pm 1.6$ & $1.853 \pm 2.1$ & $1.6 \pm 2.0$ & $1.7 \pm 1.9$ \\
\hline
\end{tabular}

$\underline{\text { Notes }}$

\begin{tabular}{|c|c|c|c|c|c|c|c|}
\hline PF & Physical Functioning & VT & Vitality & PCS & Physical Component Summary & DS & HADS Depression Score \\
\hline $\mathrm{RP}$ & Role Physical & $\mathrm{SF}$ & Social Functioning & MCS & Mental Component Summary & WM & Western Medicine \\
\hline BP & Bodily Pain & RE & Role Emotional & AS & HADS Anxiety Score & $\mathrm{CM}$ & Chinese Medicine \\
\hline
\end{tabular}

General Health

* $\quad$ Significant difference between counseling and video groups by appropriate chi-square or independent sample t-test, $\mathrm{p}<0.05$.

$\dagger \quad$ Significant difference between participants (PST-PC and placebo (video) groups) and non-participants (refused RCT) by appropriate chi-square test or independent t-test, $\mathrm{p}<0.05$. 
Table 2. Changes in SF-36 Scores, HAD Scores and Consultation Rates from Baseline

\begin{tabular}{|c|c|c|c|c|c|c|c|c|}
\hline \multirow{3}{*}{$\begin{array}{l}\text { Outcome } \\
\text { measure }\end{array}$} & \multicolumn{4}{|c|}{ PST-PC } & \multicolumn{4}{|c|}{ Video } \\
\hline & \multicolumn{4}{|c|}{ Change from Week $0(95 \% \mathrm{CI})$} & \multicolumn{4}{|c|}{ Change from Week $0(95 \% \mathrm{CI})$} \\
\hline & Week 6 & Week 12 & Week 26 & Week 52 & Week 6 & Week 12 & Week 26 & Week 52 \\
\hline PF & $-0.23(-2.62,2.15)$ & $-1.24(-3.91,1.43)$ & $-2.28(-4.75,0.19)$ & $-2.32(-4.84,0.21)$ & $0.34(-1.76,2.43)$ & $0.34(-1.85,2.53)$ & $-1(-3.28,1.29)$ & $-1.9(-4.31,0.52)$ \\
\hline $\mathbf{R P}$ & $5.7(-1.52,12.93)$ & $4.19(-2.58,10.97)$ & $-0.34(-7.32,6.65)$ & $2.35(-4.56,9.26)$ & $8.83 *(2.08,15.58)$ & $12.17 *(5.67,18.67)$ & $4.5(-2.42,11.42)$ & $6.17(-1.15,13.48)$ \\
\hline BP & $2.72(-1.22,6.66)$ & $-0.68(-5.12,3.75)$ & $0.75(-3.74,5.24)$ & $-1.11(-5.7,3.47)$ & $5.62 *(1.09,10.15)$ & $8.41 *(3.72,13.1)$ & $5.93 *(1.34,10.51)$ & $7.37 *(2.9,11.83)$ \\
\hline GH & $4.59(0.96,8.23) \dagger$ & $3.67(-0.18,7.53)$ & $1.89(-1.88,5.65)$ & $2.46(-1.46,6.38)$ & $4.67 *(0.94,8.41) \dagger$ & $6.67 *(2.71,10.62)$ & $5.09 *(1,9.17) \dagger$ & $2.35(-1.47,6.18)$ \\
\hline VT & $3.02(-0.45,6.49)$ & $-0.4(-4.31,3.5)$ & $-3.39(-7.36,0.58)$ & $-2.18(-6.05,1.69)$ & $2.5(-1.05,6.05)$ & $0(-3.49,3.49)$ & $-1.07(-4.63,2.49)$ & $-0.9(-4.45,2.65)$ \\
\hline SF & $3.1(-1.55,7.76)$ & $2.77(-2.23,7.77)$ & $1.85(-2.75,6.44)$ & $-1.76(-6.62,3.09)$ & $4.75(0.37,9.13)$ & $4.25(-0.37,8.87)$ & $5.67(0.89,10.45)$ & $2.67(-1.76,7.09)$ \\
\hline $\mathbf{R E}$ & $11.41 *(4.1,18.72)$ & $9.84 *(1.83,17.86) \dagger$ & $2.46(-5.19,10.11)$ & $3.13(-4.88,11.14)$ & $3.56(-3.68,10.79)$ & $6.89(-0.51,14.29)$ & $8.22(1.43,15.02)$ & $10.89 *(3.97,17.81)$ \\
\hline МH & $2.36(-0.4,5.13)$ & $1.15(-1.76,4.07)$ & $-0.08(-3.49,3.33)$ & $0.86(-2.31,4.03)$ & $-0.03(-2.81,2.75)$ & $-0.21(-3.47,3.04)$ & $-0.24(-3.38,2.9)$ & $-0.4(-3.31,2.51)$ \\
\hline PCS & $0.7(-1.01,2.41)$ & $-0.11(-1.98,1.76)$ & $-0.52(-2.22,1.18)$ & $-0.54(-2.18,1.09)$ & $2.25 *(0.75,3.76)$ & $3.1 *(1.52,4.69)$ & $1.15(-0.6,2.91)$ & $0.8(-0.96,2.56)$ \\
\hline MCS & $2.64 *(0.84,4.44)$ & $1.91(0.01,3.81)$ & $0.47(-1.62,2.55)$ & $0.74(-1.26,2.74)$ & $0.64(-1.23,2.5)$ & $0.29(-1.58,2.16)$ & $1.19(-0.73,3.12)$ & $1.07(-0.7,2.84)$ \\
\hline $\mathbf{A S}$ & $-0.97 *(-1.52,-0.43)$ & $-1.09 *(-1.7,-0.49)$ & $-1.29 *(-1.89,-0.68)$ & $-1.17 *(-1.84,-0.51)$ & $-1.37 *(-1.83,-0.9)$ & $-1.46 *(-1.94,-0.98)$ & $-1.68 *(-2.16,-1.2)$ & $-1.58 *(-2.09,-1.07)$ \\
\hline DS & $0.36(-0.28,0.99)$ & $0.6(-0.06,1.26)$ & $0.67(-0.02,1.36)$ & $1.13 *(0.39,1.88)$ & $0.79 *(0.12,1.47)$ & $0.87 *(0.19,1.56)$ & $0.85^{*}(0.12,1.59)$ & $1.4 *(0.67,2.13)$ \\
\hline $\begin{array}{l}\text { WM } \\
\text { episodic } \\
\text { consultation }\end{array}$ & $-0.06(-0.16,0.03)$ & $-0.09(-0.19,0.02)$ & $-0.09(-0.19,0.02)$ & $-0.11(-0.22,0)$ & $0.05(-0.05,0.15)$ & $0.01(-0.1,0.12)$ & $-0.08(-0.18,0.03)$ & $-0.03(-0.15,0.09)$ \\
\hline $\begin{array}{l}\text { Total } \\
\text { consultation }\end{array}$ & $0.01(-0.09,0.11)$ & $-0.08(-0.18,0.03)$ & $0.01(-0.11,0.12)$ & $0.03(-0.07,0.13)$ & $0.01(-0.09,0.12)$ & $0.06(-0.06,0.17)$ & $0(-0.12,0.12)$ & $0.04(-0.08,0.17)$ \\
\hline $\begin{array}{l}\text { All WM } \\
\text { consultation }\end{array}$ & $-2.58(-5.71,0.56)$ & $-2.1(-5.49,1.29)$ & $-1.28(-4.9,2.35)$ & $-1.3(-4.95,2.34)$ & $-0.54(-3.37,2.29)$ & $-1.16(-4.26,1.94)$ & $-1.29(-4.4,1.83)$ & $-0.47(-3.3,2.36)$ \\
\hline $\begin{array}{l}\text { CM } \\
\text { consultation }\end{array}$ & $0.16(-0.04,0.36)$ & $0.11(-0.09,0.32)$ & $0.83(-0.49,2.15)$ & $0.77(-0.53,2.08)$ & $0.57(-0.74,1.88)$ & $1.24(-0.59,3.07)$ & $0.73(-0.6,2.06)$ & $0.53(-0.79,1.84)$ \\
\hline
\end{tabular}

$\underline{\text { Notes }}$

$\begin{array}{llllllll}\text { PF } & \text { Physical Functioning } & \text { VT } & \text { Vitality } & \text { PCS } & \text { Physical Component Summary } & \text { DS } & \text { HADS Depression Score } \\ \text { RP } & \text { Role Physical } & \text { SF } & \text { Social Functioning } & \text { MCS } & \text { Mental Component Summary } & \text { WM } & \text { Western Medicine } \\ \text { BP } & \text { Bodily Pain } & \text { RE } & \text { Role Emotional } & \text { AS } & \text { HADS Anxiety Score } & \text { CM } & \text { Chinese Medicine }\end{array}$

GH General Health MH Mental Health

* $\quad$ Significant at 5\% level of significance after adjusting for multiplicity by Holm's procedure

$\dagger \quad$ Results after adjustment for DS and MH, socio-demographics and co-morbidity were similar except for those noted $\dagger$ 
Table 3. Estimated effects of PST-PC vs. Placebo (video) on Outcomes

\begin{tabular}{|c|c|c|c|c|c|c|}
\hline \multirow{2}{*}{$\begin{array}{l}\text { Outcome } \\
\text { variable } \\
\mathrm{PF}\end{array}$} & \multicolumn{3}{|c|}{$\begin{array}{l}\text { Unadjusted for potential } \\
\text { confounding factors }\end{array}$} & \multicolumn{3}{|c|}{\begin{tabular}{|c|}
$\begin{array}{c}\text { Adjusted for DS and MH scores at } \\
\text { baseline, as well as socio-demographics } \\
\text { and co-morbidity }\end{array}$ \\
\end{tabular}} \\
\hline & $\begin{array}{c}\text { Difference }^{\dagger} \\
-1.94\end{array}$ & $\begin{array}{c}(\mathbf{9 5 \%} \text { CI) } \\
(-4.54,0.66)\end{array}$ & $\begin{array}{c}\text { p-value } \\
0.145\end{array}$ & $\begin{array}{c}\text { Difference }^{\dagger} \\
-1.52\end{array}$ & $\begin{array}{r}(\mathbf{9 5 \%} \mathbf{C I}) \\
(-4.08,1.03)\end{array}$ & $\begin{array}{c}\text { p-value } \\
0.243\end{array}$ \\
\hline $\mathrm{RP}$ & -3.51 & $(-9.90,2.88)$ & 0.282 & -1.36 & $(-7.90,5.19)$ & 0.685 \\
\hline BP & -6.29 & $(-10.50,-2.13)$ & $0.003 *$ & -5.21 & $(-9.43,0.99)$ & 0.016 \\
\hline $\mathrm{GH}$ & -2.73 & $(-6.73,1.27)$ & 0.181 & -1.90 & $(-5.87,2.07)$ & 0.348 \\
\hline VT & -2.60 & $(-6.32,1.11)$ & 0.170 & -2.00 & $(-5.72,1.71)$ & 0.291 \\
\hline SF & -4.80 & $(-8.92,-0.67)$ & 0.023 & -4.21 & $(-8.26,-0.51)$ & 0.043 \\
\hline RE at week 6 & 2.80 & $(-3.96,9.55)$ & 0.418 & 4.08 & $(-2.62,10.78)$ & 0.233 \\
\hline RE at week 12 & 0.80 & $(-5.46,7.06)$ & 0.803 & 2.25 & $(-3.97,8.47)$ & 0.478 \\
\hline RE at week 26 & -3.86 & $(-9.63,1.90)$ & 0.189 & -2.02 & $(-7.79,3.75)$ & 0.493 \\
\hline RE at week 52 & -12.50 & $(-20.00,-5.07)$ & $0.001 *$ & -9.95 & $(-17.5,-2.39)$ & 0.010 \\
\hline $\mathrm{MH}$ & -0.70 & $(-3.71,2.31)$ & 0.649 & -0.60 & $(-3.68,2.47)$ & 0.701 \\
\hline PCS & -2.07 & $(-3.86,-0.28)$ & 0.023 & -1.48 & $(-3.25,0.30)$ & 0.103 \\
\hline MCS & -0.60 & $(-2.45,1.25)$ & 0.524 & -0.51 & $(-2.36,1.35)$ & 0.592 \\
\hline AS & 0.53 & $(-0.01,1.08)$ & 0.057 & 0.41 & $(-0.14,0.96)$ & 0.146 \\
\hline $\mathrm{DS}$ & 0.20 & $(-0.55,0.96)$ & 0.599 & 0.01 & $(-0.71,0.74)$ & 0.972 \\
\hline $\begin{array}{l}\text { WM episodic } \\
\text { consultation }\end{array}$ & -0.07 & $(-0.15,0.02)$ & 0.128 & -0.09 & $(-0.17,-0.002)$ & 0.045 \\
\hline Total consultation & -0.05 & $(-0.15,0.05)$ & 0.315 & -0.07 & $(-0.17,0.02)$ & 0.129 \\
\hline $\begin{array}{l}\text { All WM } \\
\text { consultation }\end{array}$ & 0.78 & $(-1.93,3.50)$ & 0.572 & 0.50 & $(-2.20,3.19)$ & 0.717 \\
\hline $\mathrm{CM}$ consultation & -0.25 & $(-1.25,0.76)$ & 0.630 & -0.22 & $(-1.27,0.83)$ & 0.684 \\
\hline
\end{tabular}

\section{$\underline{\text { Notes }}$}

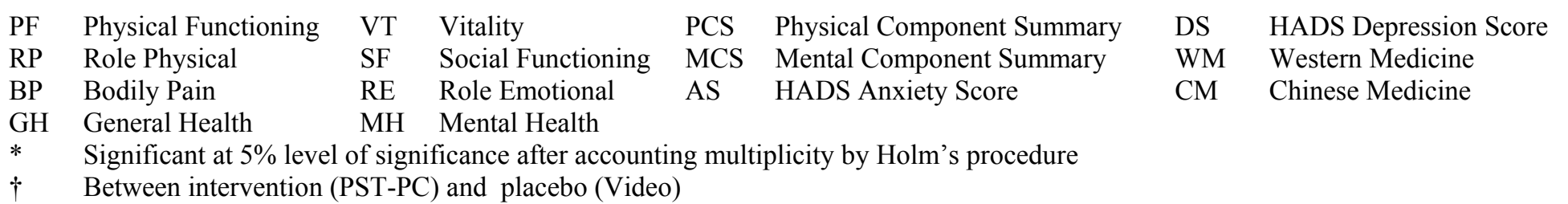


Table 4: Patient Evaluation on PST-PC and Video-viewing Sessions

\begin{tabular}{|c|c|c|c|c|}
\hline & \multicolumn{2}{|c|}{$\begin{array}{l}\text { PST-PC } \\
(\mathrm{N}=112)\end{array}$} & \multicolumn{2}{|c|}{$\begin{array}{l}\text { Placebo (Video) } \\
\qquad(\mathrm{N}=117)\end{array}$} \\
\hline Questions & $\begin{array}{l}\text { Yes } \\
\mathrm{n}(\%)\end{array}$ & $\begin{array}{l}\text { No } \\
\mathrm{n}(\%)\end{array}$ & $\begin{array}{l}\text { Yes } \\
\mathrm{n}(\%)\end{array}$ & $\begin{array}{l}\text { No } \\
\mathrm{n}(\%)\end{array}$ \\
\hline Are you willing to participate again? & $58 \quad(51.8) \dagger$ & $54(48.2) \dagger$ & $76(65.0) \dagger$ & $41(35.0) \dagger$ \\
\hline $\begin{array}{l}\text { Would you have participated if no } \\
\text { travelling allowance were provided? }\end{array}$ & $62(63.3) \dagger$ & $36(36.7) \dagger$ & $88(77.9) \dagger$ & $25(22.1) \dagger$ \\
\hline $\begin{array}{l}\text { Will you recommend others to join } \\
\text { this study? }\end{array}$ & $34(30.4) \dagger$ & $78(69.6) \dagger$ & $53(45.3) \dagger$ & $64(54.7) \dagger$ \\
\hline $\begin{array}{l}\text { Do you wish your family doctor to } \\
\text { provide similar PSC service? }\end{array}$ & $81 \quad(73.0)$ & $30(27.0)$ & & \\
\hline $\begin{array}{l}\text { Did this intervention lead to any } \\
\text { improvement in your general health? }\end{array}$ & $37 \quad(33.0) \dagger$ & $75(67.0) \dagger$ & $60(51.3) \dagger$ & $57(48.7) \dagger$ \\
\hline $\begin{array}{l}\text { Did this intervention lead to any } \\
\text { improvement in psychological } \\
\text { health? }\end{array}$ & $44 \quad(39.3)$ & $68(60.7)$ & $57(48.7)$ & $60(51.3)$ \\
\hline $\begin{array}{l}\text { Was it worth the time to join this } \\
\text { study? }\end{array}$ & $108(96.4)$ & $4(3.6)$ & $115(98.3)$ & $2(1.7)$ \\
\hline
\end{tabular}

\section{Notes}

NA Not applicable

$\dagger \quad$ Significant difference in proportions between PST-PC and Placebo (Video) groups by Chi-square test, $\mathrm{p}<0.05$. 
Appendix A: Brief PST-PC for the Elderly with Psychological Problems-Assessment \& Management Summary

\section{$\underline{\text { First Session }}$}

Date:

Subject Number :

HADS Anxiety score \& symptoms: AS: ( )

HADS Depression score \& symptoms: DS:

Psychological diagnosis (please circle the main problem):
1. Major Depression
2. Dysthymia
3. Adjustment disorder
4. Psychosomatisation
5. Hypochondriasis
6. Panic disorder
7. Generalised Anxiety
8. OCD
9. Phobia
10. Others, please specify : 99. No psychological diagnosis

Significant somatic symptoms:

Problems in living:

Ask the patient to identify their MAIN problem

Severity rating of MAIN problem

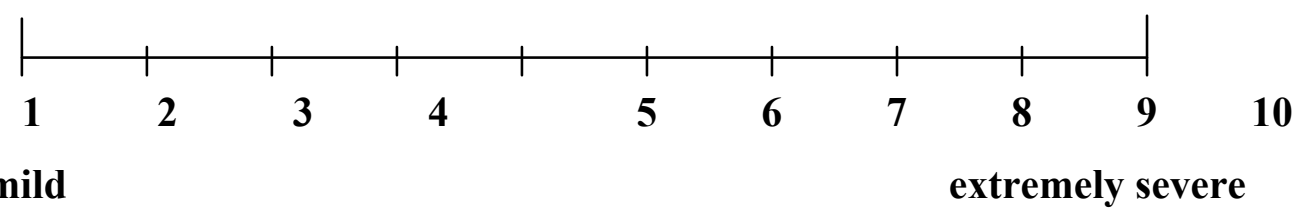

very mild

Solution plan:

Ask patient to think of possible solutions

$>$ Suggest any you can think of they haven't mentioned

List advantages and disadvantages of each possible solution

Prioritize the list; allow patient to strike out impossible solutions

Settle on their preferred solution: break it down into steps

Patient is to work on the first step of their preferred solution and report progress to you 


\section{Follow Up PSC Session}

PST Week:

Subject Number :

Ask the patient how his/her MAIN problem is getting on:

Severity rating of MAIN problem

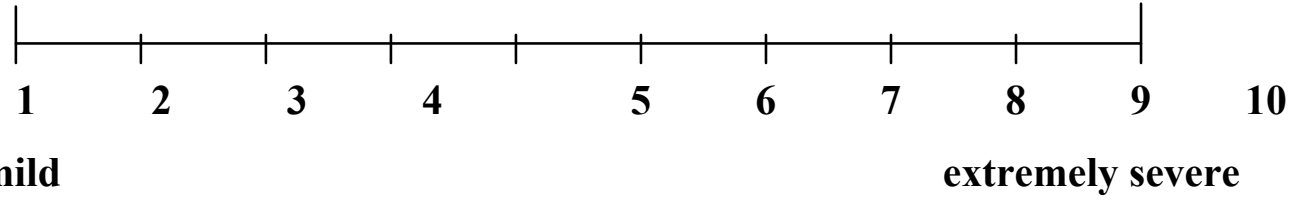

Solution plan:

Ask the patient what he/she has done to solve his/her problem:

$>$ Was it effective?

Ask patient to think of any other possible solution:

$>$ Suggest any you can think of patient has not mentioned:

$>$ List advantages and disadvantages of each possible solution:

$>$ Prioritize the list; allow patient to strike out impossible solutions:

$>$ Settle on the preferred solution: break it down into steps:

$>$ Patient is to work on the first step of their preferred solution and report progress to you 


\section{List of References}

ALEXOPOULOS, G. S., RAUE, P. \& AREAN, P. (2003) Probelm-solving therapy versus supportive therapy in geriatric major depression with executive dysfunction. Am J Geriatr Psychiatry, 11, 46-52.

AREAN, P., HEGEL, M., VANNOY, S., FAN, M. \& UNUZTER, J. (2008) Effectiveness of problem-solving therapy for older pirmary care patients with depression: results from the IMPACT Project. The Gerontologist, 48, 311-323.

BJELLAND, I., DAHL, A. A., HAUG, T. T. \& NECKELMANN, D. (2002) The validity of the Hospital Anxiety and Depression Scale: an updated literature review. $J$ Pschosomatic Res, 52, 69-77.

BOWER, P. (2002) Primary care mental health workers: models of working and evidence of effectiveness. Br J Gen Pract, 52, 926-933.

CALLAHAN, C. (2001) Quality improvement research on late life depression in primary care. Med Care, 39, 772-784.

CAPE, J., BARKER, C., BUSZEWICZ, M. \& PISTRANG, N. (2000a) General practitioner psychological management of common emotional problems (I): definitions and literature review. Br J Gen Pract . 50, 313-318.

CAPE, J., BARKER, C., BUSZEWICZ, M. \& PISTRANG, N. (2000b) General practitioner psychological management of common emotional problems (II): a research agenda for the development of evidence-based practice. Br J Gen Pract, 50, 396-400.

CENSUS \& STATISTICS DEPARTMENT (2001) Social Data Collected via the General Household Survey. Hong Kong, Census \& Statistics Department.

CHILVERS, C., DEWEY, M., FIELDING, K., GRETTON, V., MILLER, P., PALMER B., WELLER, D., CHURCHILL, R., WILLAIMS, I., BEDI, N., DUGGAN, C., LEE, A. \& HARRISON, G. (2001) Antidepressant drugs and generic counselling for treatment of major depression in primary care: randomised trial with patient preference arms. . BMJ., 322, 772-775.

DOWRICK, C., DUNN, G., AYUSO-MATEOS, J. L. \& ET AL. (2000a) Problem solving treatment and group psychoeducation for depression: multicentre randomised controlled trial. Br Med J, 321, 1450-1454.

DOWRICK, C. F., BELLON, J. A. \& GOMEZ, M. J. (2000b) GP frequent attendance in Liverpool and Granada: the impact of depressive symptoms. Br J Gen Pract, 50, 361365.

FARSIDES, B. \& DUNLOP, R. J. (2001) Measuring quality of life - Is there such a thing as a life not worth living? BMJ, 322, 1481-1483.

GILBODY, S. M., HOUSE, A. O. \& SHELDON, T. A. (2001) Routinely administered questionnaires for depression and anxiety: systematic review. Br Med J, 322, 406-409.

GRIFFITHS, K. M. \& CHRISTENSEN, H. (2009) Depression in primary health care: from evidence to policy. MJA, 188, S81-S83.

GUM, A., AREAN, P., HUNKELER, E., TANG, L., KATON, W., HITCHCOCK, P., STEFFENS, D., DICKENS, J. \& UNUTZER, J. (2006) Depression treatment preferences in older primary care patients. The Gerontologist, 46, 14-22.

HARMAN, J. S., EDLUND, M. J., FORTNEY, J. C. \& KALLAS, H. (2005) The influence of comorbid chronic medical conditions on the adequacy of depression care for older Americans. J Am Geriactr Soc, 53, 2178-2183.

HEGEL, M., BARRETT, J., CORNELL, J. \& OXMAN, T. E. (2002) Predictors of response to problem solving treatment of depression in primary care.

. Behaviour Therapy, 33, 511-527. 
HEGEL, M. T., DIETRICH, A. J., SEVILLE, J. L. \& JORDAN, C., B., (2004) Training residents in problem-solving treatment of depression: a pilot feasibility and impact study. Fam Med, 36, 204-208.

HIRSCHFELD, R. M. A. (2001) The comorbidity of major depression and anxiety disorders: recognition and management in primary care. . Primary Care Companion J Clin Psychiatry, 3, 244-254.

HOLM, S. (1979) A simple sequential rejective multiple test procedure. . Scandanavian Journal of Statistics 6, 65-70.

HUNKELER, E. M., KATON, W., TANG, L., WILLIAMS, J. W., KROENKE, K., LIN, E. H. B., HARPOLE, L. H., AREAN, P., LEVINE, S., GRYPMA, L. M.,

HARGREAVES, W. A. \& UNUTZER, J. (2006) Long term outcomes from the IMPACT randomised trial for depressed elderly patients in primary care. . BMJ, 332, 259-263.

KENNEDY, S. H., LAM, R. W. \& MORRIS, B. (2003) Clinical guidelines for depressive disorders. Canadian Family Physician, 49, 489-491.

LAM, C. L., GANDEK, B., REN, X. S. \& CHAN, M. S. (1998) Tests of scaling assumptions and construct validity of the Chinese (HK) version of the SF-36 Health Survey. J Clin Epidemiol, 51, 1139-47.

LAM, C. L., PAN, P. C., CHAN, A. W., CHAN, S. Y. \& MUNRO, C. (1995) Can the Hospital Anxiety and Depression (HAD) Scale be used on Chinese elderly in general practice? Fam Pract, 12, 149-54.

LAM, C. L. K. (1995) How does depression present in general practice? HKMJ, 1, 225-229.

LAM, C. L. K., CHIN, W. Y., LEE, P. W. H., LO, Y. Y. C., FONG, D., Y.T. \& LAM, T. P. (2009) Unrecognized psychological problems impair quality of life and increase consultation rates in Chinese elderly patients. Int J Geriatr Psychiatry, (in press).

LAM, C. L. K., LAUDER, I. J., LAM, T. P. \& GANDEK, B. (1999) Population based norming of the Chinese (HK) version of the SF-36 Health Survey. H K Pract, 21, 460-470.

LIU, S. I., MANN, A., CHENG, A., TJUNG, J. J. \& HWANG, L. C. (2004) Identification of common mental disorders by general medical doctors in Taiwan. General Hospital Psychiatry, 26, 282-288.

MALOUFF, J. M., THORSTEINSSON, E. B. \& SCHUTTE, N. S. (2007) The efficacy of problem solving therapy in reducing mental and physical health problems: a metaanalysis. Clin Psychol Review 27, 46-57.

MYNORS-WALLIS, L. (2001) Problem-solving treatmnet in general psychiatric practice. Advances in Psychiatric Treatment, 7, 417-425.

MYNORS-WALLIS, L. M., GATH, D. H., DAY, A. \& BAKER, F. (2000) Randomised controlled trial of problem solving treatment, antidepressant medication, and combined treatment for major depression in primary care. Br Med J . 320, 26-30.

NATIONAL INSTITUTE FOR CLINICAL EXCELLENCE (NICE) (2004) Depression Management of Depression in Primary and Secondary Care., National Collaborating Centre for Mental Health.

NEASE, D. E. \& MALOUIN, J. M. (2003) Depression screening: a practical strategy. J Fam Pract, 52, 118-126.

NEASE, D. E., VOLK, R. J. \& CASS, A. R. (1999) Investigation of a severity-based classification of mood and anxiety symptoms in primary care patients. J Am Board Fam Pract, 12, 21-31.

SCHREUDERS, B., VAN MARWIJK, H., SMIT, J., RIJMEN, F., STALMAN, W. \& VAN OPPEN, P. (2007) Primary care patients with mental health problems: outcome of a randomised clinical trial. 
. Br J Gen Pract 57 886-891.

SPIGSET, O. (1999) Drug treatment of depression. Br J Med, 318, 1188-1191.

STREINER, D. L., CAIRNEY, J. \& VELDHUIZEN, S. (2006) The epidemiology of psychological problems in the elderly. Can J Psychiatry, 51, 185-191.

THE MAGPIE RESEARCH GROUP (2005) The treatment of common mental health problems in general practice. Fam Pract, 23, 53-59.

U.S. PREVENTIVE SERVICES TASK FORCE (2002) Screening for depression: recommendations and rationale., Agency for Healthcare Research and Quality, Rockville, MD.

WARE, J. E. \& SHERBOURNE, C. D. (1992) The MOS 36-item Short-Form Helath Survey (SF-36) Conceptual Framework and Item Selection. Medical Care, 30, 473-383.

WARE, J. E., SNOW, K. K., KOSINSKI, M. \& GANDEK, B. (1993) SF-36 Health Survey Manual \&Interpretation Guide., Boston: The Health Institute, New England Medical Center.

WILLIAMS, J. W., BARRETT, J., OXMAN, T. \& ET AL. (2000) Treatment of dysthymia and minor depression in primary care. JAMA, 284, 1519-1526.

ZIGMOND, A. S. \& SNAITH, R. P. (1983) The hospital anxiety and depression scale. Acta Psychiatr Scand, 67, 361-370. 